\title{
Lunar cycles affect common dolphin Delphinus delphis foraging in the Southern California Bight
}

\author{
Anne E. Simonis ${ }^{1, *}$, Marie A. Roch ${ }^{1,2}$, Barbara Bailey ${ }^{2}$, Jay Barlow ${ }^{3}$, \\ Rachel E. S. Clemesha ${ }^{1}$, Sam Iacobellis ${ }^{1}$, John A. Hildebrand ${ }^{1}$, \\ Simone Baumann-Pickering ${ }^{1}$
}

\author{
${ }^{1}$ Scripps Institution of Oceanography, University of California San Diego, La Jolla, CA 92037, USA \\ ${ }^{2}$ San Diego State University, San Diego, CA 92182, USA \\ ${ }^{3}$ NOAA, Southwest Fisheries Science Center, La Jolla, CA 92037, USA
}

\begin{abstract}
In the Southern California Bight, the common dolphin Delphinus delphis is the most abundant dolphin species and preys upon small pelagic fish, mesopelagic fish, and cephalopods. Mesopelagic fish and many cephalopods are available throughout the year, and they form deep scattering layers, some of which characteristically undergo strong diel vertical migrations. The extent of vertical migration depends on the degree of sea surface solar and lunar illumination. At their daytime depth, mesopelagic prey are beyond the range of shallow-diving dolphins. Autonomous acoustic recorders were used to monitor dolphin echolocation at 2 offshore recording locations from 2009 to 2014. Manual and automated classification techniques were used to identify periods of high echolocation activity, indicative of common dolphin foraging. Clear lunar patterns existed in cool months, when echolocation activity was highest during the darkest periods of the night and lunar month, indicating times when dolphins were foraging, possibly on mesopelagic prey. Echolocation was more abundant during warm months, but diel and lunar patterns in echolocation were weaker. Generalized additive mixed models show that the observed patterns in echolocation activity are correlated with lunar day and position of the moon in the night sky. Seasonal patterns may represent geographic shifts in common dolphin populations, shoaling scattering layers, or prey switching behavior during the warm months, whereby dolphins target small pelagic fish not associated with the deep scattering layers. Overall, dolphin foraging activity declined from 2009 to 2014 during warm months, which may be related to a declining abundance of small pelagic fish.
\end{abstract}

KEY WORDS: Dolphins - Foraging - Lunar cycle · Echolocation · Deep scattering layers · Mesopelagic

\section{INTRODUCTION}

The common dolphin Delphinus delphis is one of the most widely distributed cetaceans and by far the most abundant cetacean predator in the Southern California Bight (SCB; Evans 1975, Barlow et al. 2008, Campbell et al. 2015). Two subspecies are recognized in the SCB: the short-beaked and long-beaked common dolphins $(D . d$. delphis and $D . d$. bairdii, respectively; Cunha et al. 2015). School sizes of 10s to 1000s of individuals have been observed and have been

*Corresponding author: asimonis@ucsd.edu shown to vary in size seasonally, with the largest group sizes in the SCB observed during winter months (Campbell et al. 2015). Common dolphin distribution in the region is also known to vary on seasonal and inter-annual time scales, likely related to shifting prey distributions and oceanographic conditions (Campbell et al. 2015). Opportunistic feeding behavior of common dolphins observed around the world suggests that their diet represents prey that are locally available and energy-rich (Silva 1999, Pusineri et al. 2007, Meynier et al. 2008, Spitz et al. 2010).

() University of California San Diego, San Diego State University 2017. Open Access under Creative Commons by Attribution Licence. Use, distribution and reproduction are unrestricted. Authors and original publication must be credited.

Publisher: Inter-Research · www.int-res.com 
Therefore, the foraging behavior of common dolphins may indicate the distribution and relative abundance of dolphin prey. The objective of this study is to identify patterns in common dolphin foraging behavior and consider how they may relate to potential prey.

Early tagging studies of common dolphins in the SCB showed that most deep foraging dives are made to 30 to $60 \mathrm{~m}$ depth and occur at night; only rarely did dolphins dive deeper than $200 \mathrm{~m}$ (Evans 1971). Recent studies in the same region have shown distinct diel behavioral patterns of common dolphins, where foraging mainly occurs at night and travel and social behavior occurs during the day (Henderson et al. 2012, Wiggins et al. 2013). The observed diving behavior suggests that the dolphins nocturnally feed on mesopelagic organisms which migrate to the epipelagic zone (surface to $200 \mathrm{~m}$ depth) at dusk.

Stomach content analyses confirm that vertically migrating fish and cephalopods are important prey items for common dolphins in southern California (Evans 1975, Osnes-Erie 1999) but market squid Doryteuthis opalescens, juvenile and adult small pelagic fish such as sardine Sardinops sagax or anchovy Engraulis mordax may be preferred when available (Evans 1975). Adult anchovy and sardine are most abundant in the SCB during winter and spring months, respectively (Lo et al. 2011, MacCall et al. 2016); however, populations of both fishes have been shown to dramatically fluctuate in abundance with characteristic periods of about $60 \mathrm{yr}$ (Baumgartner et al. 1992). Osnes-Erie (1999) found no significant difference in variation of the diet of common dolphins between seasons in California from 1975 to 1994; however, the diet analysis was done at the specieslevel of prey items and an alternative analysis based on functional group (e.g. mesopelagic vs. small pelagic fishes) may yield different results. The ability of common dolphins to cope with large fluctuations in prey availability on seasonal and decadal timescales suggests that they are opportunistic and can adjust foraging strategies according to local conditions.

Many mesopelagic fish and cephalopods undergo a diel vertical migration, from depth (normally below 300 to $400 \mathrm{~m}$ ) during the day (Longhurst 1976) to the epipelagic zone at night where they feed (Barham 1966, Bianchi \& Mislan 2016, Klevjer et al. 2016). Mesopelagic organisms often associate and migrate in distinct layers, called deep scattering layers (DSLs) due to their high acoustic reflectance, which produces layers of detections when observed with active sonar systems. It appears that mesopelagic fish seek refuge in dark waters and at the edges of deep oxygen minimum zones which are inaccessible or unsuitable for their more aerobic and visually oriented predators (Seibel 2011, Netburn \& Koslow 2015). Both absolute light levels, as well as the rate of change in light levels, have been proposed as triggers for changes in the behavior of vertical migrators, and there also seems to be an endogenous rhythm component to vertical migration (Benoit-Bird et al. 2009a, Ochoa et al. 2013). Lanternfish (family Myctophidae), in particular, play an important role in SCB ecosystems (Davison et al. 2015), are abundant in DSLs, and are known to occur at much lower densities in the epipelagic zone during nights surrounding the full moon versus dark nights of the new moon (Clarke 1973). However, fish density may increase at certain depths; Benoit-Bird et al. (2009b) reported increases in the scattering volume of layers during full moon periods in the nearshore habitats of Hawai'i and New Zealand, as organisms were more tightly packed vertically. In addition to light and endogenous rhythms as cues, prey distribution, bioenergetics, tidal influence, predator avoidance, and effects of commensal species may also drive vertical migrations (see review in Neilson \& Perry 1990).

Optimal foraging theory suggests that predators will minimize the cost of pursuing prey to maximize the energy gained while foraging (Pyke 1984). As such, marine predators that eat mesopelagic prey will likely track the dynamics of DSLs and adjust their response to nocturnal light conditions to maximize foraging efficiency. During full moon periods, when the vertical migration of prey is suppressed, the foraging efficiency of juvenile Galápagos fur seals Arctocephalus galapagoensis is reduced and as a result they lose weight (Horning \& Trillmich 1999). H. Glotin (unpubl. data) observed that sperm whales Physeter macrocephalus in the Mediterranean spend more time foraging during full moon periods. This may be related to increased density of their prey at shallower depths as a response to moonlight. Lowry et al. (2007) showed that catch rates in sports fisheries were well correlated with lunar cycles. Black marlin Makaira indica are physiologically limited to warmer surface waters and cannot access DSL prey during the full moon. This may make them more likely to increase their foraging effort in response to lower densities of prey (Lowry et al. 2007) and result in a positive correlation between full moon and catch rate. In contrast, mahi-mahi Coryphaena hippurus and yellowfin tuna Thunnus albacares are able to track the vertical movements of their prey and are more abundant in surface waters during the new moon. In all of these cases, the association of altered behavior during different lunar periods is attributed to the ability of these predators to access their prey. 
Dolphins use echolocation to forage and navigate, which creates an opportunity for passive acoustic monitoring to be a useful indicator of odontocete presence and behavior on timescales of hours to years (Henderson et al. 2012, Wiggins et al. 2013). Dolphin behavior, in addition to instrument sensitivity and environmental conditions, determines the spatial extent of passive acoustic monitoring. The source level of common dolphin echolocation clicks has been measured in captivity (145 to $170 \mathrm{~dB}$ re: $1 \mu \mathrm{Pa}$; Evans 1973, Fish \& Turl 1976); however, source levels measured from dolphins in highly reverberant tanks may be up to $60 \mathrm{~dB}$ lower than those observed in open-water environments (Au et al. 1974, Au 1980). Source levels for free-ranging common dolphins may be similar to the source levels measured in open-ocean environments for other dolphins with similar body sizes, including whitebeaked Lagenorhynchus albirostris, spinner Stenella longirostris and spotted $S$. attenuata dolphins (190 to $220 \mathrm{~dB}$ re: $1 \mu \mathrm{Pa}$; Rasmussen et al. 2002, Schotten et al. 2004). Properties of echolocation signals may change according to the task; e.g. dolphins may decrease the source level of their clicks with decreasing target range (Au \& Benoit-Bird 2003). Given the high frequency energy content of echolocation clicks, attenuation from the source to the receiver can be significant. From the surface to a bottom-moored instrument $1000 \mathrm{~m}$ away, the transmission loss associated with spherical spreading and absorption for a signal at $30 \mathrm{kHz}$ in $15^{\circ} \mathrm{C}$ water, is $\sim 66 \mathrm{~dB}$ (Urick 1983). The directional beam pattern of outgoing echolocation clicks $\left(-30 \mathrm{~dB}\right.$ at $>30^{\circ}$ off axis of the clicks central beam for a bottlenose dolphin; Au 1993) will further limit the detection range for off-axis clicks. Individuals in actively foraging groups of common dolphins in the SCB have been observed to change direction frequently while consistently echolocating, resulting in a constant stream of clicks that arrive to the receiver while a group is actively foraging nearby (Wiggins et al. 2013). Traveling behavior is captured in the acoustic record as a more fleeting and compact bout of click detections, while socializing behavior would be associated with many fewer click detections (Wiggins et al. 2013). The expected detection range for a foraging group of dolphins will depend on many factors, including the number of individuals and orientation of the group; however, considering the behavior and transmission loss for shallow-diving dolphins like common dolphins, the expected detection range for a foraging group may vary from 1.5 to $5 \mathrm{~km}$ from a seafloor sensor (Frasier et al. 2016). Variation in daily, monthly, and seasonal acoustic activity provides information about how dolphins exploit available resources.

In this study, passive acoustic recordings were analyzed to determine the echolocation behavior of common dolphins in the SCB from 2009 to 2014. Based on the behavior of other predators that feed on DSL organisms, we hypothesized that common dolphin foraging ability would be impeded and that echolocation behavior would be depressed during full moon periods of the lunar cycle. We identified patterns in echolocation activity at daily and monthly timescales in cool seasons (November-April) and warm seasons (May-October). A relationship between dolphin acoustic behavior and the lunar cycle was explored between different seasons through a regression analysis. We considered how the patterns in acoustic behavior may relate to dolphin foraging, local light conditions and the behavior of locally available prey.

\section{MATERIALS AND METHODS}

\section{Acoustic recordings}

Autonomous high-frequency acoustic recording packages (HARPs; Wiggins \& Hildebrand 2007) were deployed on the seafloor at 2 locations in the SCB (Fig. 1) with the hydrophone positioned about $30 \mathrm{~m}$ above the seafloor. One recorder was placed at Site 1 at a depth of $1300 \mathrm{~m}, 50 \mathrm{~km}$ southwest of San Clemente Island $\left(32^{\circ} 50.55^{\prime} \mathrm{N} 119^{\circ} 10.27^{\prime} \mathrm{W}\right)$ and the other was at Site 2 at a depth of $900 \mathrm{~m}, 58 \mathrm{~km}$ west of San Clemente Island $\left(32^{\circ} 22.19^{\prime} \mathrm{N} \quad 118^{\circ} 33.77^{\prime} \mathrm{W}\right)$.

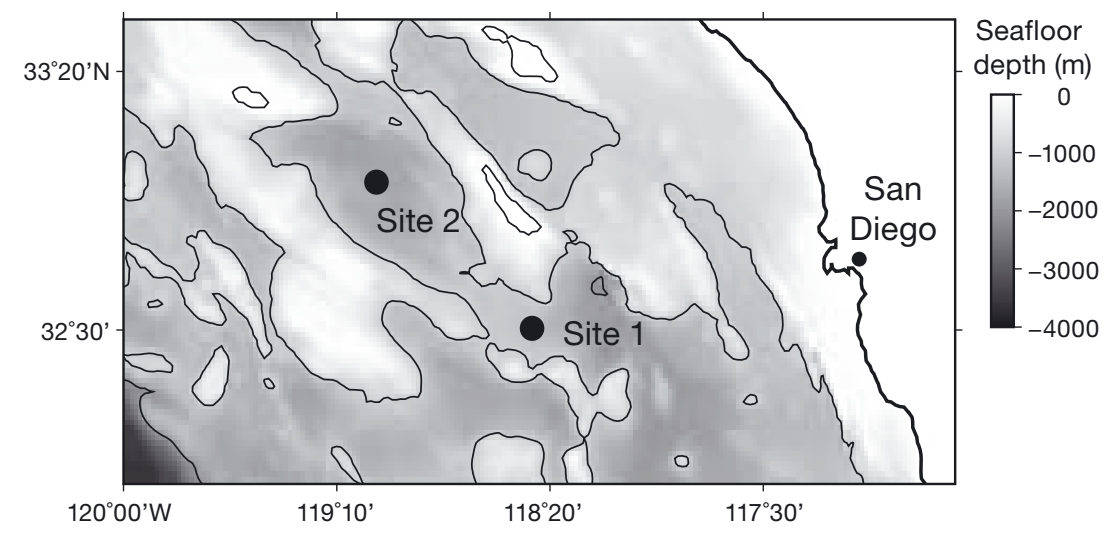

Fig. 1. Map of the Southern California Bight showing the 2 recording locations. Thin lines are $1000 \mathrm{~m}$ depth countours 
These instruments were part of an earlier, long-term acoustic monitoring project throughout the SCB and were chosen for this analysis based on the concurrent multi-year time series and the year-round presence of common dolphins at each location. There were multiple deployments from January 2009 to December 2014. All HARPs continuously collected recordings at a sampling rate of $200 \mathrm{kHz}$ with 16-bit quantization, although there were gaps in coverage due to equipment servicing (see horizontal bars on top of each panel in Fig. 4). The hydrophone used was an omni-directional sensor (ITC-1042, International Transducer Corporation, Santa Barbara, CA), which had an approximately flat $( \pm 2 \mathrm{~dB})$ hydrophone sensi-

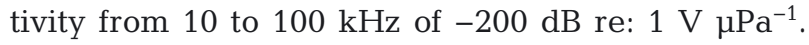
Each system contained a custom-built preamplifier board and bandpass filter (Wiggins \& Hildebrand 2007). The calibrated system response was accounted for during analysis.

\section{Acoustic data analysis}

Signal processing was performed using the custom software program Triton (Wiggins \& Hildebrand 2007) and other MATLAB custom routines. Individual echolocation signals were automatically detected using a computer algorithm with a 2-step approach (Soldevilla et al. 2008, Roch et al. 2011) and a minimum peak-to-peak received level threshold was set to $120 \mathrm{~dB}$ re: $1 \mu \mathrm{Pa}$. This received level was defined based on a manual review of the detection data to determine the received level at which echolocation clicks were no longer reliably detected. Long-term spectral averages (LTSAs) were calculated to visually inspect long-term recordings. LTSAs are similar to spectrograms, but each time bin contains an average of 500 non-overlapped Hann-windowed 10 ms frames whose spectra have been averaged with the algorithm from Welch (1967) resulting in $5 \mathrm{~s}$ time bins with $100 \mathrm{~Hz}$ resolution. Trained analysts manually screened 1 hour windows of LTSAs and identified acoustic encounters of echolocation in the HARP data while recording the presence of species-specific echolocation signals of Pacific white-sided Lagenorhynchus obliquidens and Risso's Grampus griseus dolphins based on the click descriptions described in Soldevilla et al. (2008) in order to exclude these species from this analysis. Acoustic encounters with Cuvier's Ziphius cavirostris and unidentified beaked whale species were classified according to the methods outlined in Baumann-Pickering et al. (2013) and excluded from this analysis.
There is an offshore population of bottlenose dolphins consistently present in the Southern California Bight (Forney \& Barlow 1998) whose echolocation clicks cannot currently be distinguished from common dolphins. The most recent 2014 abundance estimates for Southern California suggest population sizes of $624503(\mathrm{CV}=0.15)$ and $52331(\mathrm{CV}=0.39)$ for short and long-beaked common dolphins, respectively and 5585 (CV = 0.42) for bottlenose dolphins (Barlow 2016). From 1991 to 2014 in the California Current, the mean group size was 190 and 482 for short and long-beaked common dolphins, respectively, and 13.3 for bottlenose dolphins (Barlow 2016). Also, sightings of offshore bottlenose dolphins in the SCB are typically concentrated in nearshore areas around the Channel Islands (Hamilton et al. 2009) and would not be within the acoustic detection range of the HARPs used in this study. The low density, small group sizes, and known distribution of bottlenose dolphins in the SCB indicate that the probability of detecting clicks that exceed the thresholds used in this study that are not attributable to common dolphins is low. Consequently, any misclassification of acoustic encounters are unlikely to bias the overall observed patterns. See 'Discussion' for consideration of other potentially confounding species.

Acoustic features including the mean spectra and inter-click intervals have been shown to be distinct between encounters of different dolphin species (Madsen et al. 2004, Frasier 2015), and both features are used here to classify encounters of common dolphins. Click detections were divided into $30 \mathrm{~min}$ time periods and further inspected. First, the mean spectrum of all click detections within each $30 \mathrm{~min}$ time period was manually reviewed to identify false or anomalous detections. Any spectra with dominant low frequencies $(<20 \mathrm{kHz})$, narrowband, or anomalous energy content were further inspected. Encounters with anomalous characteristics were reviewed using an LTSA, along with plots of peak-topeak received level, inter-click-interval, and mean spectrum (Fig. S1 in the Supplement at www.int-res. com/articles/suppl/m577p221_supp.pdf) to determine correct and false detections of echolocation activity that could be attributed to common dolphins.

There was a predominant mode in inter-click intervals around $50 \mathrm{~ms}$ during acoustic encounters with dolphins (Figs. S1 \& S2B). Thirty-six $30 \mathrm{~min}$ time periods $(<1 \%$ of total time periods with detections) contained dolphin echolocation concurrent with false detections from ship noise or mid-frequency active sonar. In these cases, it was prohibitively time-consuming to separate the echolocation clicks from the 
other signals. An analyst estimated the click metrics for these time periods. To verify that the spectral content of all detections was similar, the mean click spectra from 30 min time periods were plotted as spectrograms and arranged by increasing peak frequencies (a random sample of $10 \%$ of all time periods is plotted in Fig. S2A). Intense low-frequency energy $(<20 \mathrm{kHz})$ in time periods with verified echolocation detections was reviewed and verified as being attributable to concurrent delphinid whistles and echolocation. Given the elimination of known signals, the consistent features of detected echolocation clicks, and the known distribution of dolphin species in the $\mathrm{SCB}$, the detections considered in this analysis can confidently be attributed to common dolphins.

\section{Regression analysis}

To infer behavior from the acoustic record, the actual number of echolocation clicks received is not as diagnostic as the presence of echolocation bouts. Our definition for the presence or absence of echolocation in each 5 min time period is based on a minimum number of click detections. The mode of observed inter-click intervals was $50 \mathrm{~ms}$, likely reflecting a typical inter-click interval used by common dolphins. Considering that dolphins are frequently changing direction while foraging, along with the highly directional nature of echolocation clicks, it is unlikely that all echolocation clicks from nearby dolphins will be detected at the receiver. Two sets of thresholds were used in our analysis of echolocation clicks as a proxy for foraging behavior. In both cases, thresholds were motivated by the 6000 clicks that a dolphin would produce while clicking continuously over 5 min with a $50 \mathrm{~ms}$ inter-click interval, with the assumption that at least one of the dolphins would be detectable at any given time. As there are still large differences in detectability of off-axis echolocation clicks for animals that are not close to the hydrophone, we considered both lenient 10\% (600 clicks) and strict 100\% (6000 clicks) thresholds.

Predictor variables were chosen to consider the explanatory effects of various components of the lunar cycle that are known to influence behavioral dynamics of DSLs and may influence the acoustic behavior of dolphins (Table 1). Predictors included categorical factors such as the recording location (site), calendar month and year, occurrence before, during or after the moon was visible in the night sky (moon presence), as well as continuous predictors such as lunar day (0-29, with Day 15 = full moon) considered as a cyclical predictor, normalized time between sunset and sunrise [0,1], and apparent magnitude of moonlight. Moon presence accounts for the relative differences in timing of moonrise and sunset throughout the lunar cycle. For nights when the moon was never present in the night sky, the 'moon presence' predictor for all times of the night was labeled as 'before.' Lunar magnitude and lunar day were never combined in a single model due to the high correlation of these predictors. Nighttime cloud cover metrics were included when available. Interactions between the predictors were also considered. In addition to variance in illumination from the moon, cloud cover may reduce localized light levels. Low-level marine stratus clouds are a highly persistent feature in the SCB during warmer months and have higher albedo than thin, high clouds, therefore low level clouds were

Table 1. Predictors used in model selection and analysis of nighttime dolphin echolocation activity

\begin{tabular}{|c|c|c|}
\hline Predictor & Type & Description \\
\hline Recording location & Categorical & Site 1 or 2 \\
\hline Month & Categorical & Calendar month (January = 1, December = 12) \\
\hline Year & Categorical & Calendar year $(2009,2010$, etc.) \\
\hline Moon presence & Categorical & $\begin{array}{l}\text { Occurrence before, with, or after the moon is present in the sky over the } \\
\text { course of one night }\end{array}$ \\
\hline Cloud presence & Categorical & $\begin{array}{l}\text { Presence or absence of cloud cover. Data available May-September } \\
\text { 2009-2014 }\end{array}$ \\
\hline Lunar day & Cyclic & $\begin{array}{l}\text { Lunar Day }[1,29] \\
1=\text { new moon, } 15=\text { full moon }\end{array}$ \\
\hline Normalized time of night & Continuous & Normalized time of night $[0,1]$ between sunset and sunrise \\
\hline Apparent lunar magnitude & Continuous & $\begin{array}{l}\text { Brightness of the moon on the apparent magnitude scale. } \\
\text { New moon }=0 \\
\text { Full moon }=-12.9\end{array}$ \\
\hline
\end{tabular}


used to best track cloud conditions with potential to reduce surface light levels (Iacobellis \& Cayan 2013, Schwartz et al. 2014). Using methods described by Clemesha et al. (2016), remotely sensed low cloud cover was estimated at $30 \mathrm{~min}$ intervals during May to September on a $4 \times 4 \mathrm{~km}$ grid. Cloud coverage data were not available for the entire year as these methods cannot reliably estimate cloud cover during October to April. At each grid cell, low clouds were assessed as present or absent. Clouds were considered to be present if low clouds were detected in at least 2 of the 4 grid cells surrounding each HARP location.

To predict the presence of echolocation in a $5 \mathrm{~min}$ time period, we used generalized additive mixed models (GAMMs), which can account for lack of independence in time series measurements. GAMMs were built using various predictors during both cool (November-April) and warm (May-October) seasons across multiple years. Each year was divided into separate cool and warm seasons based on deviations from the mean sea surface temperature at the pier of Scripps Institution of Oceanography (SIO Shore Stations program; www.shorestation.ucsd.edu). Scatterplots, histograms and boxplots of each explanatory variable were checked for extreme values and severe non-normality, which would violate model assumptions (Zuur et al. 2009). GAMM analysis was carried out using the 'mgcv' package (Wood 2004) in the R statistical software, version 3.3.0 (Wood 2006, R Development Core Team 2016). The mgcv parameter gamma was set at 1.4 as recommended by Wood (2006) to avoid overfitting. To simplify analysis due to the different patterns observed in each season, separate models were built for cool and warm seasons, as opposed to including a monthly or seasonal interaction factor with each predictor. Due to the binary nature of the data (presence or absence of echolocation), we used a binomial distribution with a logistic link function. The link function contains an intercept and multiple smoothing functions, describing nonlinear effects of lunar and seasonal cycles on echolocation behavior. The smoothing functions for continuous predictors were estimated by cubic regression splines (cyclic cubic regression splines for periodic predictors like lunar day) and the optimal level of smoothing was estimated using cross-validation (Wood 2006).

Various models were fitted using different subsets of the explanatory variables. All were fit in a stepwise fashion, dropping predictors individually and selecting the model with the maximum log-likelihood. Models for warm seasons were fitted with and without cloud cover as a factor. Remotely sensed cloud coverage estimates for each recording location were available at $30 \mathrm{~min}$ intervals for select warm months (May-September) only. When included, the presence or absence of clouds was considered as a factor with an interaction effect with lunar day. For the partial warm season datasets including cloud cover, the same model selection process was conducted. Model performance was also assessed with a 4 -fold cross-validation procedure in which 4 models were trained on $75 \%$ of the data and predictions on the remaining $25 \%$ were combined and compared to observations.

\section{RESULTS}

The majority (62\%) of 5 min observation periods at both recording locations contained no detected echolocation clicks. For click-positive observation periods, the median number of detections was 284 with a range of 1 to 58977 . The median peak-to-peak received level for detections in each 5 min bin had a range of 120 to $149 \mathrm{~dB}$ re: $1 \mu \mathrm{Pa}$ with a mean $+\mathrm{SD}$ of $126 \pm 3 \mathrm{~dB}$ re: $1 \mu \mathrm{Pa}$. Deeper-diving dolphins may result in higher received levels in click detections, so the distribution of the 90th percentile of received levels within each 5 min time period was investigated throughout the lunar month and between seasons using 2-sample K-S tests. Within cool months, there were significant differences in the distribution of the 90th percentiles of received levels of dolphin clicks in 5 min time periods from the 3 days around the new and full moons (K-S test, $\mathrm{p}<0.0001$ ), and the mean value was $\sim 1.5 \mathrm{~dB}$ higher during the full moon (full moon mean $=128.8 \pm 3 \mathrm{~dB}$ re: $1 \mu \mathrm{Pa}$, new moon mean $=127.3 \pm 3 \mathrm{~dB}$ re: $1 \mu \mathrm{Pa}$ ). In the warm season, the mean value of the 90th percentiles of 5 min time periods was also higher during nights of the full moon by $\sim 1 \mathrm{~dB}$ (full moon mean $=127.9 \pm 3 \mathrm{~dB}$ re: $1 \mu \mathrm{Pa}$, new moon mean $=127.1 \pm 3 \mathrm{~dB}$ re: $1 \mu \mathrm{Pa}$ ) and the K-S test indicated there were significant differences in the distributions (K-S test, $\mathrm{p}<0.0001)$.

At both sites, temporal patterns and the relationship of echolocation presence with explanatory variables using both the 600-detection and 6000-detection thresholds were similar; as such, only the 600-detection threshold is presented here. Distinct diel, lunar, and seasonal patterns of common dolphin echolocation activity were observed throughout the recording period (Figs. $2 \& 3$ ) and were similar at both sites. Throughout the year, echolocation activity showed a diel pattern, with most echolocation occur- 


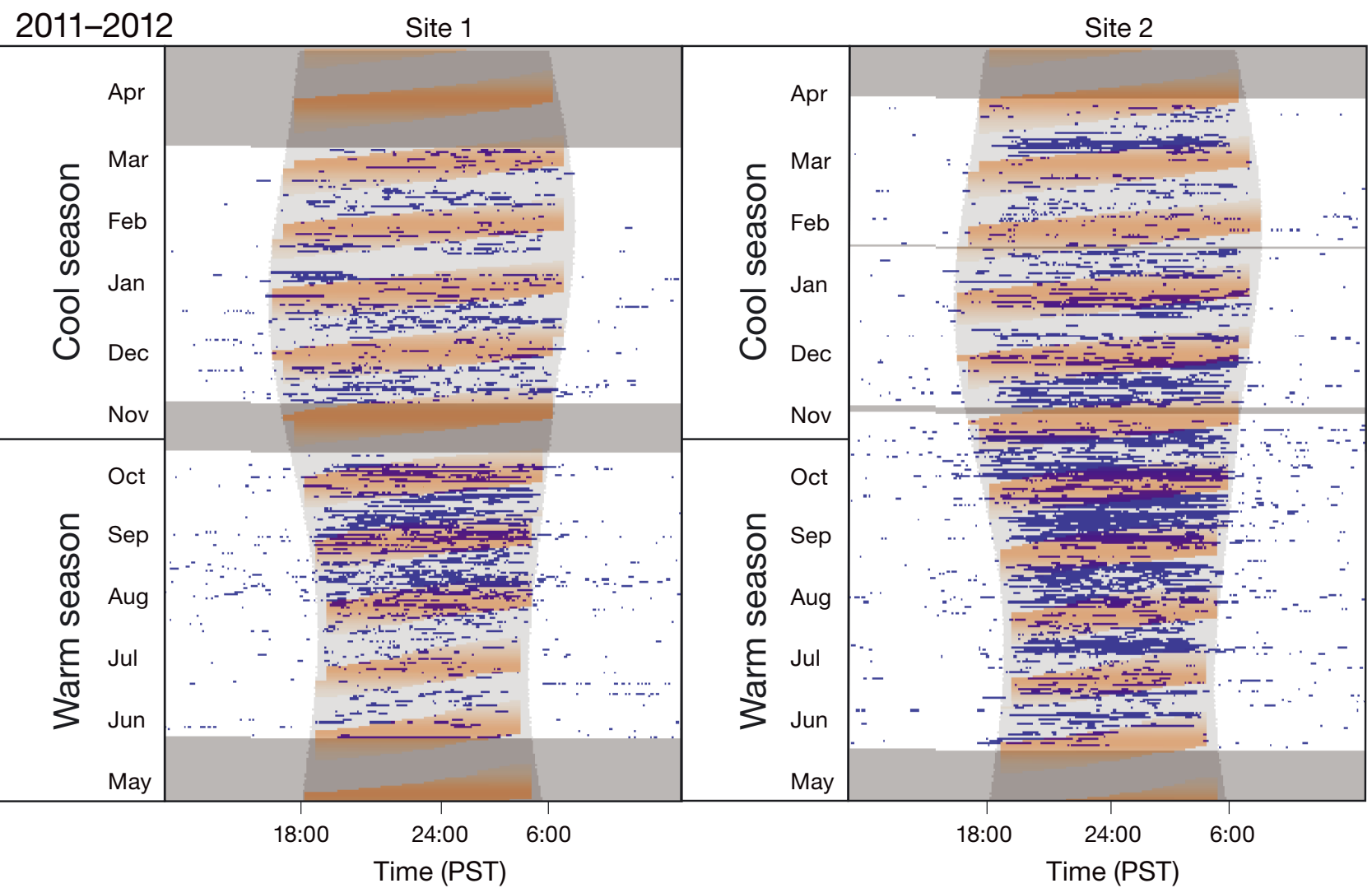

Fig. 2. One year (May 2011-April 2012) of common dolphin echolocation activity (blue shading) at the 2 sites. Detections are plotted in 5 min time periods across an entire day, centered on midnight, with light gray shading indicating nighttime periods. Presence indicates a minimum of 600 detections per 5 min period. Nighttime lunar illumination is shaded orange and acquired in 5 min bins. Dark gray horizontal boxes indicate periods of no recordings. PST: Pacific standard time

Cool season

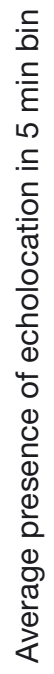

Fig. 3. Nighttime observations (2009-2014) of the presence of echolocation per 5 min time period for each site shown with explanatory variables including lunar day, presence of the moon, year, normalized time of night, and month. Cloud coverage data is only available for May-September each year. Two-day averages are shown for lunar day for ease of visibility. Lunar cycle begins with new moon at Day 1 and full moon at Day 15 

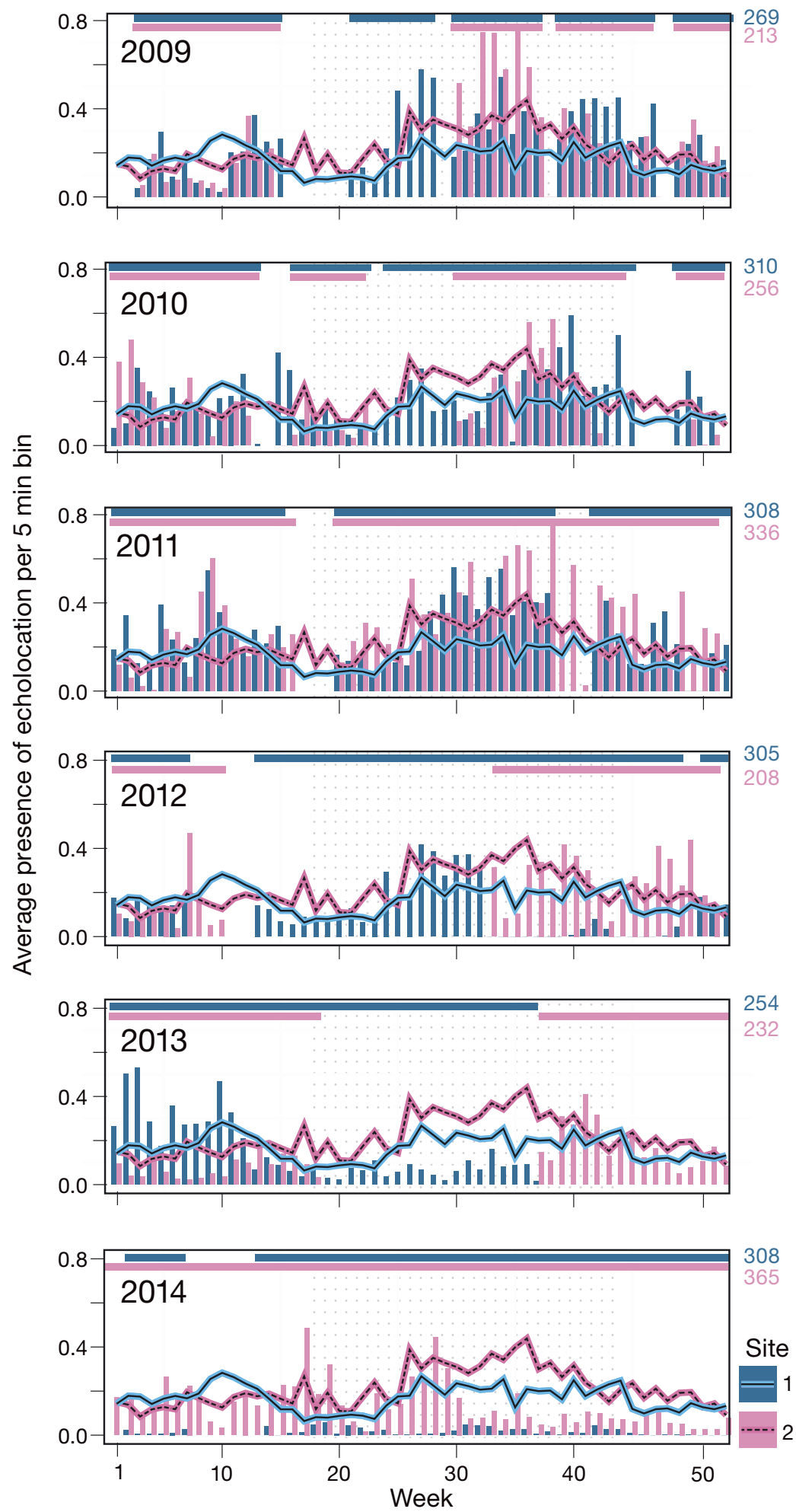

Fig. 4. Average weekly presence (bars) of echolocation in 5 min time periods for the 2 study sites. Lines show weekly values averaged across the years 2009-2014. Colored, horizontal bars on top of each panel show recording periods, and the associated colored numbers on the right are the total annual number of days with recordings for each site. Weeks in the warmer months of the year (May-October) are indicated by dotted background ring at night (Fig. 2). Nighttime echolocation was lowest during crepuscular periods and most abundant at the midpoint between sunrise and sunset (Fig. 3). From 2009 to 2011, there was also a seasonal pattern at both sites, with reduced echolocation activity during May through June (weeks 18-24; Figs. 3 \& 4) and elevated echolocation activity was observed in August and September (weeks 31-39). In the years 2012 and 2013, there was not sufficient recording effort at both locations to determine seasonality. Echolocation activity during 2014 was much lower than all previous years, and diel, lunar, and seasonal cycles of echolocation were not apparent (Figs. $3 \& 4$ ).

Throughout the year at both sites, nighttime echolocation activity was reduced during the nights directly before, during, and after the full moon (Figs. 2 \& 3). This lunar pattern was most obvious and consistent during cool months, although there were also occasional warm months in which echolocation activity was depressed during full moon periods (Figs. $2 \& 3$ ). During the cool season, echolocation was also depressed at times when the moon was present in the night sky, but not necessarily full (Fig. 3).

At both sites during May-June, echolocation was lower than in later warm months (July-September) and, overall, echolocation activity was reduced in each successive warm season from 2010 to 2014 (Fig. 3). Compared to cool months, echolocation was more consistent throughout the lunar cycle during the warm season; however, there were some warm months that showed a decrease in echolocation around the nights of the full moon, especially at Site 2 (Fig. 3). During warm months with available cloud cover data (May to September 2009-2014), the long-term average nighttime cloudiness was $58 \%$ for Site 1 and $54 \%$ for Site 2. Although the reduction of echolocation near full moon nights was not strong in warm months, when clouds were present, there was more echolo- 


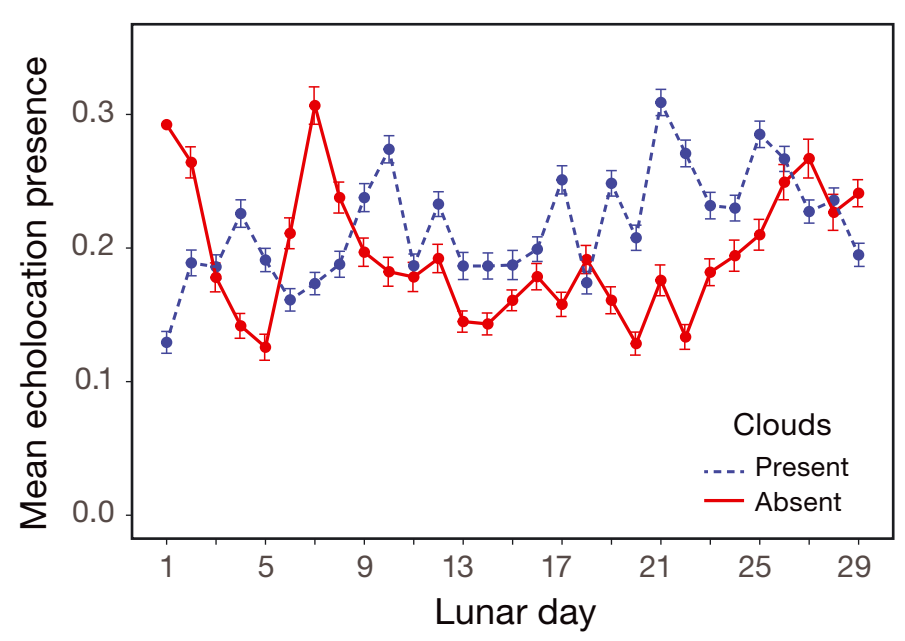

Fig. 5. Mean (+SE) presence of echolocation in 5 min time periods by lunar day (Lunar day 1 and 29 = new moon) for times with clouds absent and present ficant at the $95 \%$ confidence level; therefore, this model was chosen as the final model. The parameter estimates were similar to the original model, but the standard errors were adjusted and are slightly larger. Visual inspection of the histogram and normal quantile plot of the residuals indicate that the residuals are approximately normal, with the exception of some deviation in the tails of the distribution.

For both warm and cool seasons, the best GAMMs included explanatory variables for lunar day, normalized time of night, month, year, site, and presence of the moon (Table 2, Fig. 6). Reduced moonlight conditions due to cloud coverage was considered as an interaction effect between lunar day and cloud coverage. For warm months with available cloud coverage data, this interaction improved model fit. During the cool season, the smoothing function for lunar day reflected reduced echolocation during the nights of cation activity on nights surrounding the full moon than during the nights near the new moon, suggesting a behavioral response to surface light conditions (Fig. 5).

\section{Regression analysis}

The regression analysis was designed to identify drivers of the observed lunar patterns and did not incorporate the dynamics of large-scale environmental conditions that might induce geographic shifts in dolphin distributions. Consequently, the anomalously low observations of echolocation in 2014 were not included in the GAMMs.

An examination of the autocorrelation function (ACF) plot of the residuals indicated that there was significant autocorrelation remaining in the residuals. To account for first- and second-order autoregression, respective $\mathrm{AR}(1)$ and $\mathrm{AR}(2)$ models for the residuals were included in 2 additional GAMM fits. The second-order autoregression model had the lowest AIC, and the ACF values of the residuals for the first 5 time lags were not signi-
Table 2. Generalized additive mixed model (GAMM) estimates of predictors for nighttime echolocation periods during cool (Nov-Apr) and warm (May-Oct) seasons of 2009-2013. GAMM estimates of predictors in warm months with available cloud cover data (May-September) are also shown. Only estimates from the best models are shown here. Data from 2014 were not included due to anomalously low numbers of observations. The selected explanatory variables in each model were identified as smooth functions or factors along with their estimated degrees of freedom in parentheses and approximate $\mathrm{p}$-value significance. $\mathrm{n}=$ number of observations for each model. ${ }^{*} \mathrm{p}<0.05,{ }^{* *} \mathrm{p}<0.01,{ }^{* * *} \mathrm{p}<0.001$

\begin{tabular}{|c|c|c|c|}
\hline & $\begin{array}{l}\text { Cool season } \\
(\mathrm{n}=188450)\end{array}$ & $\begin{array}{l}\text { Warm season } \\
(\mathrm{n}=163542)\end{array}$ & $\begin{array}{l}\text { Warm season with } \\
\text { clouds }(\mathrm{n}=95514)\end{array}$ \\
\hline \multicolumn{4}{|l|}{ Smooth functions } \\
\hline Normalized time of night & $7.97(9.00)^{* * *}$ & $8.57(9.00)^{* * *}$ & \\
\hline Lunar day & $5.56(8.00)^{* * *}$ & $6.81(8.00)^{* * *}$ & \\
\hline Lunar day: cloud $=0$ & & & $5.07(8.00)^{* * *}$ \\
\hline Lunar day: cloud = 1 & & & $2.58(8.00)^{*}$ \\
\hline \multicolumn{4}{|l|}{ Factors } \\
\hline Month 6 & & $0.38(0.10)^{* * *}$ & $0.40(0.10)^{* * *}$ \\
\hline Month 7 & & $1.16(0.09)^{* * *}$ & $1.18(0.10)^{* * *}$ \\
\hline Month 8 & & $1.36(0.09)^{* * *}$ & $1.3(0.09)^{* * *}$ \\
\hline Month 9 & & $1.46(0.09)^{* * *}$ & $1.41(0.09)^{* * *}$ \\
\hline Month 10 & & $1.28(0.09)^{* * *}$ & \\
\hline Month 11 & $0.32(0.07)^{* * *}$ & & \\
\hline Month 12 & $0.25(0.25)^{* * *}$ & & \\
\hline Month 2 & $0.14(0.06)^{*}$ & & \\
\hline Month 3 & $0.29(0.07)^{* * *}$ & & \\
\hline Month 4 & $0.20(0.08)^{*}$ & & \\
\hline Site 2 & $-0.16(0.04)^{* * *}$ & $0.47(0.04)^{* * *}$ & $0.61(0.05)^{* * *}$ \\
\hline Year 2010 & $0.40(0.07)^{* * *}$ & $-0.11(0.06)$ & $-0.41(0.08)^{* * *}$ \\
\hline Year 2011 & $0.95(0.07)^{* * *}$ & $0.62(0.06)^{* * *}$ & $0.50(0.07)^{* * *}$ \\
\hline Year 2012 & $0.76(0.07)^{* * *}$ & $-0.02(0.06)$ & $0.03(0.07)$ \\
\hline Year 2013 & $0.61(0.07)^{* * *}$ & $-0.74(0.08)^{* * *}$ & $-1.33(0.11)^{* * *}$ \\
\hline Moon presence (during) & $-0.23(0.05)^{* * *}$ & $-0.04(0.05)$ & $-0.21(0.06)^{* * *}$ \\
\hline Moon presence (after) & $-0.07(0.07)$ & $0.12(0.07)$ & $-0.34(0.07)^{* * *}$ \\
\hline
\end{tabular}




\section{Cool season}
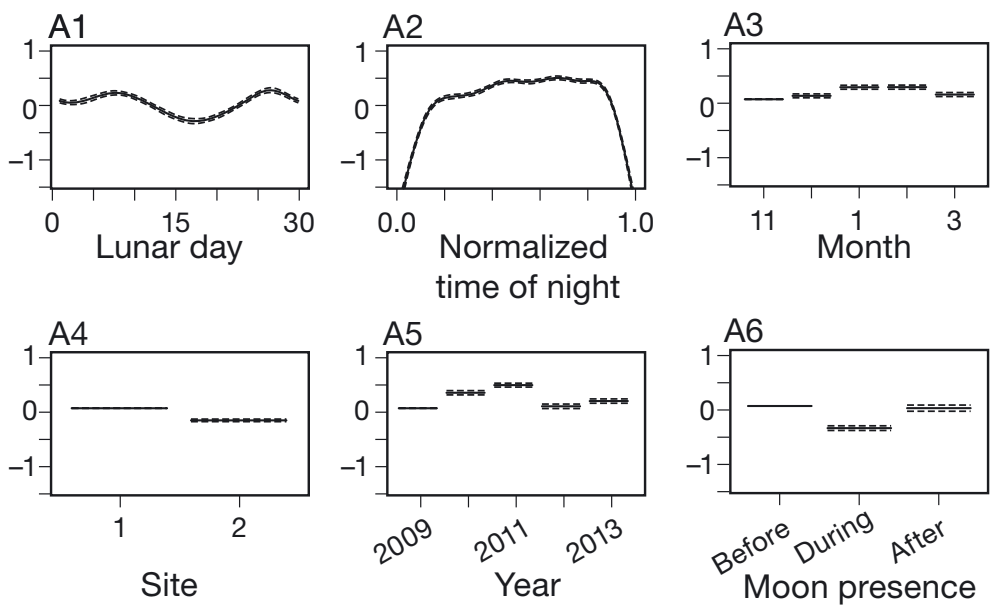

Warm season
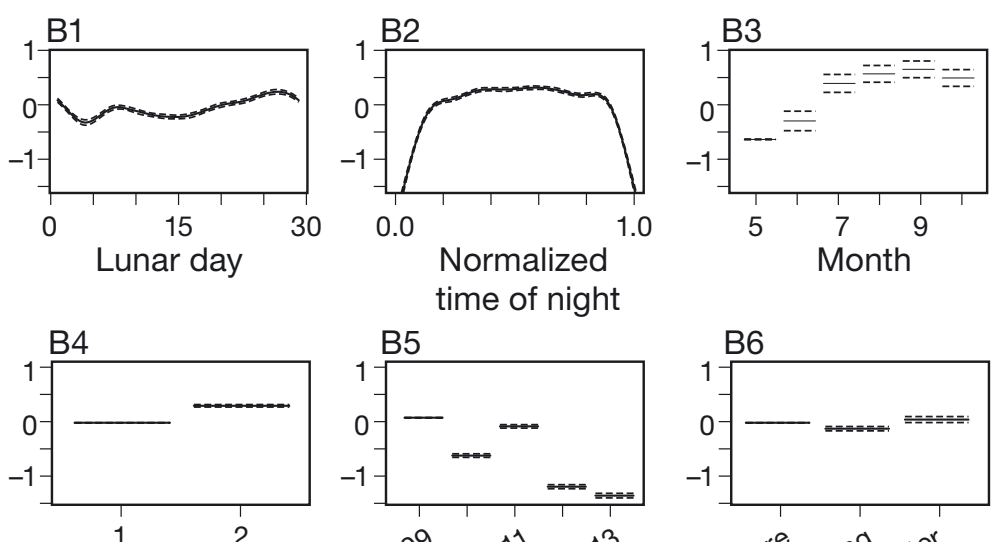

1 2

Site
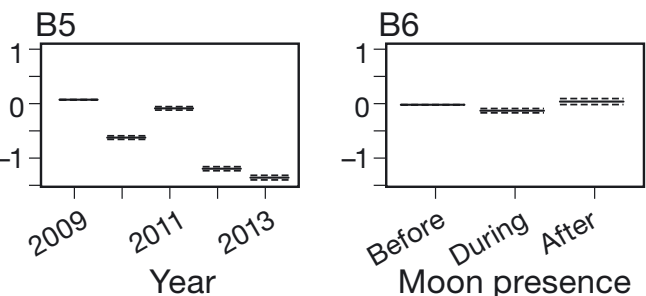

Fig. 6. Estimated smoothing curves (A1, A2, B1, B2) and factors (A3-A6, B3-B6) of nighttime GAMMs for cool and warm seasons. Zero on the vertical axes corresponds to no effect of the explanatory variable. Dashed lines indicate $95 \%$ confidence limits

and around the full moon, during the hours immediately after sunset and before sunrise and while the moon was present in the night sky (Fig. 6: A1, A2, A6). The smoothing functions for the warm season show a weaker and less obvious relationship between echolocation, lunar day, and moon presence (Fig. 6: B1, B6); however, there is a progressive increase in echolocation activity from May to October (Fig. 6: B3). Similar to the cool season, echolocation was reduced in the hours following sunset and before sunrise (Fig. 6: B2). The smoothing function for the interaction between cloudiness and lunar day shows reduced echolocation during nights surrounding the full moon, in the absence of clouds (Fig. S3: C1 in the Supplement.

\section{Predictive ability}

Contiguous $5 \mathrm{~min}$ observation periods were grouped by night and nights were randomly assigned to 4 testing and training datasets. A 4-fold cross-validation procedure trained 4 models on $75 \%$ of the data and then made predictions on the remaining $25 \%$ of the dataset. Peaks in predicted echolocation activity closely tracked periods of observed echolocation around nights of the new moon and during dark periods of the night before or after the moon was present in the night sky (Fig. 7, Figs. S4, S5 \& S6 in the Supplement). In both warm and cool seasons, the highest predicted echolocation was during the last quarter of the lunar month, when there were extended periods of darkness after sunset before the moon rose in the night sky (Fig. 7). The predicted values in cool months followed a strong lunar cycle with lowest abundance of echolocation predicted in nights surrounding the full moon and while the moon was present in the sky (Fig. S5). Predictions for warm months showed a weaker assocation with the lunar cycle and presence of moon in the sky (Fig. S4). For times during the warm months with available cloud cover data, predictions of more abundant echolocation were associated with cloud coverage (Fig. S6) which reflects observations. Predictions more closely followed observations for cool seasons than warm seasons.

\section{DISCUSSION}

Common dolphin echolocation activity showed consistent diel, lunar, and seasonal patterns from 2009 to 2013 at 2 deep, offshore locations. The observed patterns in common dolphin foraging corresponded to behavioral patterns of mesopelagic and small pelagic organisms during cool and warm months, respectively. Echolocation activity was predominantly nocturnal, confirming the findings of previous acoustic studies that showed nighttime being an important foraging time for common dolphins (Henderson et al. 2012, Wiggins et al. 2013). The acoustic record also indicated reduced echolocation activity between April and June, similar to the low regional abun- 

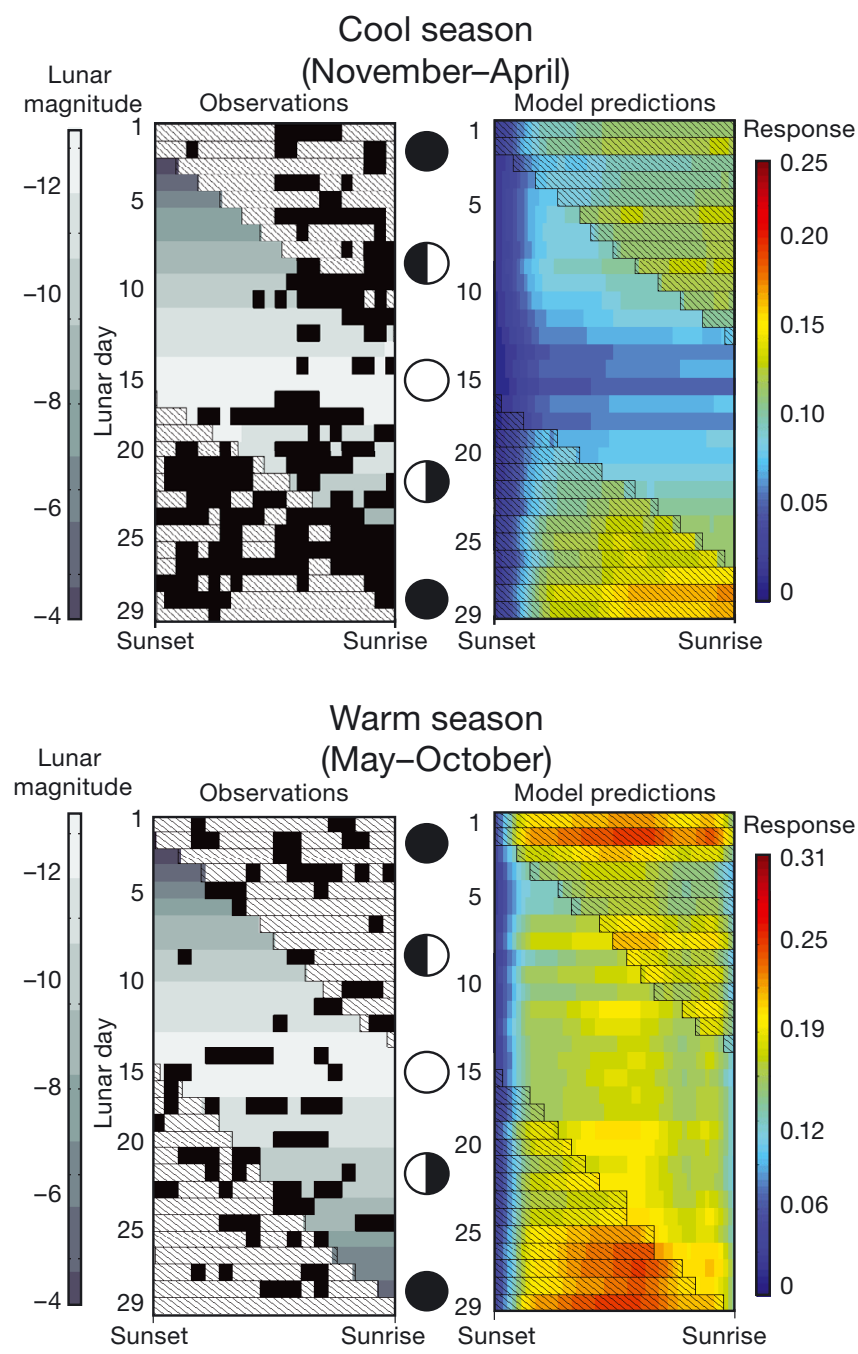

Fig. 7. Nighttime echolocation observations and model predictions from cross-validation: this example shows lunar months from cool (12/16/2009 to 1/14/2010 Site 2) and warm $(6 / 01 / 2011$ to $6 / 30 / 2011$, Site 1$)$ seasons. For both sites, predictions and observations are comparable among months for each season. Hatched areas indicate times of the night before or after the moon is present in the night sky. Black boxes indicate time periods that have met or exceeded the detection threshold to indicate the presence of echolocation. Blue-gray shading indicates lunar magnitude and cool to hot colors indicate prediction values of 4 -fold cross-validation of GAMMs. Lunar cycle begins with new moon at Day 1 and full moon is at Day 15. Central shaded circles indicate moon phase

dance of common dolphins observed in visual surveys during this time, reported by Campbell et al. (2015). There was a clear and significant relationship between echolocation activity and the lunar cycle during cool months and a weaker yet still significant relationship in warm months.

During cool months at both recording locations, the lowest rates of nocturnal echolocation were observed during nights of and around the full moon, when the moon is brightest and present in the night sky during most of the night. Low rates of echolocation may indicate horizontal or vertical shifts, reduced local foraging behavior or a switch in foraging behavior from acoustic to visual predation. The most consistent periods of echolocation were associated with the darkest times of the night and the darkest nights of the lunar cycle. During cool months, when echolocation was observed in the presence of moonlight, it most often occurred on nights near the new or quarter moon periods, when moonlight conditions are dimmer than full moon nights (Fig. 7). Model predictions highlighted a maximum in echolocation activity during the last quarter of the lunar month when there is an extended period of darkness after sunset, before the moon is present in the night sky. During these nights, mesopelagic prey may migrate toward the surface in the darkness until they are suddenly vulnerable to predators when the moon rises, as observed in freshwater zooplankton (Gliwicz 1986). Increased dolphin foraging activity during these nights might compensate for reduced opportunities during nights around the full moon or potentially relate to a lunar-mediated behavioral response of their prey.

Vertical or horizontal movements away from the HARP during full moon periods would impact detectability of echolocating dolphins, which could explain the lunar patterns observed here. There were small, but significant differences between the received level of echolocation clicks between nights surrounding the new and full moons throughout the year. Given a bottom-moored instrument at a depth of $1000 \mathrm{~m}$, the transmission loss due to absorption and spherical spreading for a signal at $30 \mathrm{kHz}$ in $15^{\circ} \mathrm{C}$ water would be about $3 \mathrm{~dB}$ greater for a dolphin foraging at $50 \mathrm{~m}$ depth compared to at $100 \mathrm{~m}$ (Urick 1983). However, received levels are also influenced by the orientation of the animal and the echolocation task being performed. The slight ( 1 to $1.5 \mathrm{~dB}$ ) difference in received levels between nights of the new and full moons, could be due to the lower transmission losses associated with dolphins diving deeper or nearer to the HARP; however, this difference could also result from a different orientation of the animal or echolocation task being performed. The current data cannot determine the depth, orientation or horizontal distance of dolphins from the recorder.

Although diel, lunar and seasonal patterns were similar between the 2 locations, the 'site' improved model fit, indicating that there are differences between common dolphin acoustic behavior at the 2 recording locations. During warm months, the lunar 
day and presence of the moon in the sky showed a significant but weak influence on echolocation, especially at Site 2 (Table 2, Fig. 3). Site 1 was slightly deeper with steeper local bathymetry compared to Site 2, but there are no known differences in community composition between these 2 locations.

During the warm season, observations of higher levels of echolocation on nights with clouds present (Fig. 5) corroborates earlier observations in the SCB of tagged common dolphins that continued to forage during daylight hours on cloudy days (Evans 1974). Low-level marine stratus clouds are a highly persistent feature alongshore and offshore of the California coastline (Iacobellis \& Cayan 2013) and may contribute to increased foraging opportunities for dolphins during both nighttime and daytime periods by reducing epipelagic light conditions and encouraging vertical migrants to stay near the surface. As cloud coverage does not follow the same predictable cycle of light levels as associated with the lunar cycle, these observations suggest that dolphins, and possibly their prey, may be responding to unpredictable short-term changes in light conditions. If reliable analysis methods become available for assessing cloud coverage in cool months, it may be useful to observe if increased cloudiness provides dolphins with enhanced opportunities to prey upon vertically migrating organisms throughout the year.

Common dolphin nocturnal echolocation becomes more consistent throughout the lunar cycle, showing little variation between nights of the new and full moon, during the transition from cool to warm seasons in the SCB, when strong coastal upwelling begins. Increased upwelling stimulates primary productivity, which affects the water transparency and dissolved oxygen concentrations. The extent and variation of vertical migration of DSLs varies with dissolved oxygen concentration (Netburn \& Koslow 2015), as well as water transparency (Isaacs et al. 1974), and has been shown to vary across seasons (Urmy et al. 2012), latitude (Tont 1976, Hazen \& Johnston 2010) and in regions of high productivity (Isaacs et al. 1974, Kaartvedt et al. 1996). In years of low oxygen, the decline of midwater fish abundance may be attributed to increased vulnerability to predation as DSLs move into more illuminated waters (Koslow et al. 2011). The largest declines in midwater oxygen in the SCB are observed during July-September (Bograd et al. 2008), which closely corresponds to the months where we observed consistent nocturnal echolocation throughout the lunar month. The consistent echolocation throughout warm season lunar cycles could indicate that shoaling DSLs are more accessible to dolphin predation, but it could also indicate that dolphins are pursuing alternative, non-vertically migrating prey as mesopelagic fish abundance declines. Future studies are encouraged to track the vertical and horizontal movements, abundance, and community composition of DSLs across seasons and in varying conditions of hypoxia.

The seasonal shift in foraging behavior during nights of the full moon may reflect seasonal preyswitching behavior. In the Atlantic, common dolphins are known to choose energy-rich prey over low-quality prey, even when low-quality prey are abundant in the environment (Spitz et al. 2010). Coastal pelagic fish species (CPS) are a preferred prey for common dolphins in the Pacific (Fitch \& Brownell 1968, Evans 1975, Osnes-Erie 1999) and are known to respond to the onset of the upwelling season and changing oceanographic conditions. Spawning aggregations of Pacific sardine are present in offshore areas of the SCB (Checkley et al. 2000, Hill et al. 2017) during spring months (March-May), although the geographic distribution of spawning aggregations may shift from inshore to offshore areas from year to year (Zwolinski et al. 2012, Hill et al. 2017). CPS species vertically migrate from depths of 15 to $70 \mathrm{~m}$ during the day to form loose surface aggregations at night (Cutter \& Demer 2008). Even during the day, CPS would be well within the normal preferred foraging depths of common dolphins, which may explain the shift to more prevalent daytime echolocation activity during warm months. Further, the highest commercial catch rates of Pacific sardine and other CPS including northern anchovy are recorded during summer months (Hill et al. 2017), corresponding with a diminished relationship between lunar cycles and dolphin echolocation. The results from the acoustic record we present here may be attributable to preyswitching behavior between oceanographic seasons, with dolphins depending on organisms associated with the DSL during cool months and switching to incorporate more abundant and energy rich CPS in warm months.

There also seems to be a link between declining abundance in local CPS and reduced echolocation activity during warm seasons from 2010 to 2013. There was no associated decline observed in cool months during these years, and common dolphin abundance in the California Current was at a record high in 2014 (Barlow 2016). Considering survey years between 1951 and 2011, anchovy abundance in southern California has been more than one standard deviation below the mean since 2005, and the lowest abundance ever recorded occurred in 2011 (Wells et 
al. 2014, MacCall et al. 2016). The sardine stock biomass estimates have been decreasing throughout the California Current since 2007, and recruitment in 2010 and 2013 was the weakest in recent history (Hill et al. 2017). The lack of CPS in Southern California waters may have driven the dolphins to seek alternative foraging grounds during warmer months. Future studies that concurrently measure dolphin activity and prey distribution and abundance are needed to determine how common dolphins respond to seasonal changes in oceanography and prey availability.

Echolocation activity throughout 2014 was so low that this time period was not included in regression analyses. During 2014, the normally vigorous upwelling season was the weakest and shortest observed since the 1990s (Peterson et al. 2015) and surface waters were anomalously warm due to the presence of the 'blob' (Hartmann 2015). In 2014 there was also an influx of anomalous 'warm water' marine mammals, tropical sea birds and turtles to the SCB (Barlow 2016). The community composition of lower trophic levels also shifted from a cold-water to a warm-water assemblage (Peterson et al. 2015), and there was a lack of evidence of spawning for record low Pacific sardine populations in 2014 and 2015 (Hill et al. 2017). The dramatic shifts in dolphin echolocation activity may be linked to the anomalous physical and biological characteristics of the California Current and merits further investigation.

Different acoustic behavior between seasons is not attributed to other dolphin species observed in the California Current, such as bottlenose, northern right whale Lissodelphis borealis or striped dolphins Stenella coeruleoalba. Although these species are not currently acoustically recognizable, northern right whale and striped dolphins are rarely observed at the recording locations, and there are very few bottlenose dolphins sighted in offshore areas (Hamilton et al. 2009). Common dolphins are by far the most abundant cetacean at the recording locations (Barlow et al. 2008, Campbell et al. 2015, Barlow 2016), and any falsely classified detections would be unlikely to bias the overall observed patterns. While it is unlikely that other dolphin species are represented in the acoustic record presented here, a seasonal geographic shift in common dolphin populations could introduce dolphins with alternative foraging preferences to this study area. Warm water conditions are associated with large-scale northward shifts of common dolphin populations, with populations from the eastern tropical Pacific and the Pacific coast of Mexico possibly moving into California waters (IATTC 1997, Carretta et al. 2016). The seasonal difference in foraging behavior described here may reflect the combined foraging effort of converging populations with varying preferences for vertically and non-vertically migrating prey.

\section{CONCLUSIONS}

Here we report a relationship between common dolphin echolocation activity and the lunar cycle throughout the year at 2 offshore locations in the $\mathrm{SCB}$. The relationship between echolocation and the lunar cycle is strongest during cooler months and seems to match the expected vertical migration of organisms within deep scattering layers. We believe that the strong relationship between lunar cycles and echolocation behavior corresponds to the importance of mesopelagic prey during cooler months. Seasonal differences in acoustic behavior may be related to dynamic upwelling and dissolved oxygen conditions, the migration of CPS, geographic shifts in common dolphin populations, and changes in the foraging strategies of dolphins. While some behaviors linked to the lunar cycle may be based on an endogenous rhythm, the dolphins also demonstrated a response to unpredictable changes in the light environments due to cloud cover. The ability to respond to changes in oceanographic conditions and community composition on seasonal timescales may buffer dolphin populations from the dramatic historical cycles observed in CPS populations.

Acknowledgements. The authors thank R. Griswold, J. Hurwitz, B. Thayre, and Erin O'Neill for fieldwork, gear, and analysis assistance. The manuscript was also improved through the thoughtful review of David Checkley and 4 anonymous reviewers. Funding for instrumentation, data collection and analysis was provided by US Office of Naval Research, Michael Weise; US Navy Living Marine Resources, Frank Stone, Robert Gisiner and Anurag Kumar; US Pacific Fleet, Chip Johnson; and the Bureau of Ocean Energy Management, Jim Price.

\section{LITERATURE CITED}

Au WWL (1980) Long-range target detection in open waters by an echolocating Atlantic bottlenose dolphin (Tursiops truncatus). J Acoust Soc Am 68:1077

$\mathrm{Au}$ WWL (1993) The sonar of dolphins. Springer-Verlag, New York, NY

Au WWL, Benoit-Bird KJ (2003) Automatic gain control in the echolocation system of dolphins. Nature 423: 861-863

Au WWL, Floyd RW, Penner RH, Murchison AE (1974) Measurement of echolocation signals of the Atlantic bottlenose dolphin, Tursiops truncatus Montagu, in open waters. J Acoust Soc Am 56:1280-1290 
Barham EG (1966) Deep scattering layer migration and composition: observations from a diving saucer. Science 151: 1399-1403

Barlow JP (2016) Cetacean abundance in the California Current estimated from ship-based line-transect surveys in 1991-2014. NOAA Adm Rep LJ-16-01

Barlow J, Kahru M, Mitchell BG (2008) Cetacean biomass, prey consumption, and primary production requirements in the California Current ecosystem. Mar Ecol Prog Ser 371:285-295

Baumann-Pickering S, McDonald MA, Simonis AE, Solsona Berga A and others (2013) Species-specific beaked whale echolocation signals. J Acoust Soc Am 134:2293-2301

Baumgartner TR, Soutar A, Ferreira-Bartrina V (1992) Reconstruction of the history of Pacific sardine and northern anchovy populations over the past two millennia from sediments of the Santa Barbara Basin, California. CCOFI Rep 33:24-40

Benoit-Bird KJ, Au WWL, Wisdom DW (2009a) Nocturnal light and lunar cycle effects on diel migration of micronekton. Limnol Oceanogr 54:1789-1800

* Benoit-Bird KJ, Dahood AD, Würsig B (2009b) Using active acoustics to compare lunar effects on predator-prey behavior in two marine mammal species. Mar Ecol Prog Ser 395:119-135

Bianchi D, Mislan KAS (2016) Global patterns of diel vertical migration times and velocities from acoustic data. Limnol Oceanogr 61:353-364

Bograd SJ, Castro CG, Di Lorenzo E, Palacios DM, Bailey H, Gilly W, Chavez FP (2008) Oxygen declines and the shoaling of the hypoxic boundary in the California Current. Geophys Res Lett 35:L12607

Campbell GS, Thomas L, Whitaker K, Douglas AB, Calambokidis J, Hildebrand JA (2015) Inter-annual and seasonal trends in cetacean distribution, density and abundance off southern California. Deep Sea Res II 112:143-157

Carretta JV, Forney KA, Oleson E, Weller DW and others (2016) US Pacific Draft Marine Mammal Stock Assessments: 2016. National Oceanic and Atmospheric Administration. http://www.nmfs.noaa.gov/pr/sars/pdf/pac 2016_draft.pdf

Checkley DM Jr, Dotson RC, Griffith DA (2000) Continuous, underway sampling of eggs of Pacific sardine (Sardinops sagax) and northern anchovy (Engraulis mordax) in spring 1996 and 1997 off southern and central California. Deep-Res II 47:1139-1155

Clarke T (1973) Some aspects of the ecology of lanternfishes (Myctophidae) in the Pacific Ocean near Hawaii. Fish Bull 71:401-434

Clemesha RES, Gershunov A, Iacobellis SF, Williams AP, Cayan DR (2016) The northward march of summer low cloudiness along the California coast. Geophys Res Lett 43:1287-12951

Cunha HA, de Castro RL, Secchi ER, Crespo EA and others (2015) Molecular and morphological differentiation of common dolphins (Delphinus sp.) in the Southwestern Atlantic: testing the two species hypothesis in sympatry. PLOS ONE 10:e0140251

Cutter GR, Demer DA (2008) California Current ecosystem survey 2006 acoustic cruise reports for NOAA FSV Oscar Dyson and NOAA FRV David Starr Jordan. NOAA Tech Memo NMFS-SWFSC-415

Davison P, Lara-Lopez A, Koslow AJ (2015) Mesopelagic fish biomass in the southern California Current ecosystem. Deep Sea Res II 112:129-142
Evans WE (1971) Orientation behavior of delphinids: radio telemetric studies. Ann NY Acad Sci 188:142-160

* Evans WE (1973) Echolocation by marine delphinids and one species of freshwater dolphin. J Acoust Soc Am 54:191

Evans WE (1974) Radio-telemetric studies of two species of small odontocete cetaceans. In: Schevill WE, Norris KS, Carleton Ray G (eds) The whale problem: a status report. Harvard University Press, Cambridge, MA, p 385-394

Evans WE (1975) Distribution, differentiation of populations, and other aspects of the natural history of Delphinus delphis linnaeus in the northeastern Pacific. PhD Thesis. University of California, Los Angeles, CA

Fish JF, Turl CW (1976) Acoustic source levels of four species of small whales. Nav Undersea Cent Tech Publ NUC TP 547, San Diego, CA

Fitch JE, Brownell RL Jr (1968) Fish otoliths in cetacean stomachs and their importance in interpreting feeding habits. J Fish Res Board Canada 25:2561-2574

Forney KA, Barlow JP (1998) Seasonal patterns in the abundance and distribution of California cetaceans, 19911992. Mar Mammal Sci 14:460-489

Frasier KE (2015) Density estimation of delphinids using passive acoustics: A case study in the Gulf of Mexico. PhD Thesis. Unversity of California San Diego, CA

* Frasier KE, Wiggins SM, Harris D, Marques TA, Thomas L, Hildebrand JA (2016) Delphinid echolocation click detection probability on near-seafloor sensors. J Acoust Soc Am 140:1918-1930

Gliwicz MZ (1986) Predation and the evolution of vertical migration in zooplankton. Nature 320:746-748

Hamilton TA, Redfern JV, Barlow JP, Ballance LT and others (2009) Atlas of cetacean sightings for Southwest Fisheries Science Center cetacean and ecosystem surveys 1986-2005. NOAA Tech Memo NMFS-SWFSC-440

*Hartmann DL (2015) Pacific sea surface temperature and the winter of 2014. Geophys Res Lett 42:1894-1902

* Hazen EL, Johnston DW (2010) Meridional patterns in the deep scattering layers and top predator distribution in the central equatorial Pacific. Fish Oceanogr 19:427-433

* Henderson EE, Hildebrand JA, Smith MH, Falcone EA (2012) The behavioral context of common dolphin (Delphinus sp.) vocalizations. Mar Mamm Sci 28:439-460

Hill KT, Crone PR, Zwolinski JP (2017) Assessment of the Pacific sardine resource in 2017 for US management in 2017-18. NOAA Tech Memo NMFS-SWFSC-576

*Horning M, Trillmich F (1999) Lunar cycles in diel prey migrations exert a stronger effect on the diving of juveniles than adult Galápagos fur seals. Proc Biol Sci 266: 1127-1132

Iacobellis SF, Cayan DR (2013) The variability of California summertime marine stratus: Impacts on surface air temperatures. J Geophys Res Atmos 118:9105-9122

IATTC (1997) Annual report of the Inter-American Tropical Tuna Commission 1995. Inter-American Trop Tuna Comm, La Jolla, CA

Isaacs JD, Tont SA, Wick GL (1974) Deep scattering layers: vertical migration as a tactic for finding food. Deep Sea Res Oceanogr Abstr 21:651-656

Kaartvedt S, Melle W, Knutsen T, Skjoldal HR (1996) Vertical distribution of fish and krill beneath water of varying optical properties. Mar Ecol Prog Ser 136:51-58

Klevjer TA, Irigoien X, Røstad A, Fraile-Nuez E, BenítezBarrios VM, Kaartvedt S (2016) Large scale patterns in vertical distribution and behaviour of mesopelagic scattering layers. Sci Rep 6:19873 
Koslow JA, Goericke R, Lara-Lopez A, Watson W (2011) Impact of declining intermediate-water oxygen on deepwater fishes in the California Current. Mar Ecol Prog Ser 436:207-218

Lo NCH, Macewicz BJ, Griffith DA (2011) Spawning biomass of Pacific sardine (Sardinops sagax) off U.S. in 2011. NOAA Tech Memo NMFS-SWFSC-486

Longhurst A (1976) Vertical migration. In: Cushing DH, Walsh $\mathrm{J}$ (eds) The ecology of the seas. Blackwell Publishing, Oxford, p 116-137

Lowry M, Williams D, Metti Y (2007) Lunar landings relationship between lunar phase and catch rates for an Australian gamefish-tournament fishery. Fish Res 88: $15-23$

MacCall AD, Sydeman WJ, Davison PC, Thayer JA (2016) Recent collapse of northern anchovy biomass off California. Fish Res 175:87-94

Madsen PT, Kerr I, Payne R (2004) Echolocation clicks of two free-ranging, oceanic delphinids with different food preferences: false killer whales Pseudorca crassidens and Risso's dolphins Grampus griseus. J Exp Biol 207: 1811-1823

Meynier L, Pusineri C, Spitz J, Santos MB, Pierce GJ, Ridoux $\mathrm{V}$ (2008) Intraspecific dietary variation in the short-beaked common dolphin Delphinus delphis in the Bay of Biscay: importance of fat fish. Mar Ecol Prog Ser 354:277-287

Neilson JD, Perry RI (1990) Diel vertical migrations of marine fishes: an obligate or facultative process? Adv Mar Biol 26:115-168

Netburn AN, Koslow JA (2015) Dissolved oxygen as a constraint on daytime deep scattering layer depth in the southern California Current ecosystem. Deep Sea Res I 104:149-158

* Ochoa J, Maske H, Sheinbaum J, Candela J (2013) Diel and lunar cycles of vertical migration extending to below $1000 \mathrm{~m}$ in the ocean and the vertical connectivity of depthtiered populations. Limnol Oceanogr 58:1207-1214

Osnes-Erie LD (1999) Food habits of common dolphin (Delphinus delphis and D. capensis) off California. MSc Thesis, San Jose State University, CA

Peterson W, Robert M, Bond NA (2015) The warm blob continues to dominate the ecosystem of the northern California Current. PICES Press 23:44-47

Pusineri C, Magnin V, Meynier L, Spitz J, Hassani S, Ridoux $\mathrm{V}$ (2007) Food and feeding ecology of the common dolphin (Delphinus delphis) in the oceanic northeast Atlantic and comparison with its diet in neritic areas. Mar Mamm Sci 23:30-47

Pyke G (1984) Optimal foraging theory. Annu Rev Ecol Syst 15:523-575

R Development Core Team (2016) R: A language and environment for statistical computing. $\mathrm{R}$ Foundation for Statistical Computing, Vienna

Rasmussen MH, Miller LA, Au WWL (2002) Source levels of clicks from free-ranging white-beaked dolphins (Lagenorhynchus albirostris Gray 1846) recorded in Icelandic waters. J Acoust Soc Am 111:1122-1125

Roch MA, Klinck H, Baumann-Pickering S, Mellinger DK, Qui S, Soldevilla MS, Hildebrand JA (2011) Classification of echolocation clicks from odontocetes in the Southern California Bight. J Acoust Soc Am 129:467

Editorial responsibility: Peter Corkeron, Woods Hole, Massachusetts, USA
Schotten M, Au WWL, Lammers MO, Aubauer R (2004) Echolocation recordings and localizations of wild spinner dolphins (Stenella longirostris) and pantropical spotted dolphins (Stenella attenuata) using a four hydrophone array. In: Thomas JA, Moss CF, Vate M (eds) Echolocation in bats and dolphins. The University of Chicago Press, Chicago, IL

* Schwartz RE, Gershunov A, Iacobellis SF, Cayan DR (2014) North American west coast summer low cloudiness: broadscale variability associated with sea surface temperature. Geophys Res Lett 41:3307-3314

Seibel BA (2011) Critical oxygen levels and metabolic suppression in oceanic oxygen minimum zones. J Exp Biol 214:326-336

Silva MA (1999) Diet of common dolphins, Delphinus delphis, off the Portuguese continental coast. J Mar Biol Assoc UK 79:531-540

* Soldevilla MS, Henderson EE, Campbell GS, Wiggins SM, Hildebrand JA, Roch MA (2008) Classification of Risso's and Pacific white-sided dolphins using spectral properties of echolocation clicks. J Acoust Soc Am 124:609-624

* Spitz J, Mourocq E, Leauté JP, Quéroe J, Ridoux V (2010) Prey selection by the common dolphin: fulfilling high energy requirements with high quality food. J Exp Mar Biol Ecol 390:73-77

Tont SA (1976) Deep scattering layers: patterns in the Pacific. CCOFI Rep 18:112-117

Urick RJ (1983) Principles of underwater sound, 3rd edn. McGraw-Hill, New York, NY

Urmy SS, Horne JK, Barbee DH (2012) Measuring the vertical distributional variability of pelagic fauna in Monterey Bay. ICES J Mar Sci 69:184-196

Welch PD (1967) The use of fast fourier transform for the estimation of power spectra: a method based on time averaging over short, modified periodograms. IEEE Trans Audio Electroacoust 15:70-73

Wells BK, Brodeur RD, Field JC, Weber E and others (2014) Coastal pelagics and forage fishes. CCIEA Phase III Rep 2013

Wiggins SM, Hildebrand JA (2007) High-frequency Acoustic Recording Package (HARP) for broad-band, long-term marine mammal monitoring. International Symposium on Underwater Technology 2007 and International Workshop on Scientific Use of Submarine Cables \& Related Technologies 2007. Institute of Electrical and Electronics Engineers, Tokyo, p 551-557

Wiggins SM, Frasier KE, Henderson EE, Hildebrand JA (2013) Tracking dolphin whistles using an autonomous acoustic recorder array. J Acoust Soc Am 133:3813-3818

Wood SN (2004) Stable and efficient multiple smoothing parameter estimation for generalized additive models. J Am Stat Assoc 99:673-686

Wood SN (2006) Generalized additive models: an introduction with R. CRC Press, Boca Raton, FL

Zuur AF, Ieno EN, Walker N, Saveliev AA, Smith GM (2009) Mixed effects models and extensions in ecology with R. Springer, New York, NY

Zwolinski JP, Demer DA, Byers KA (2012) Distributions and abundances of Pacific sardine (Sardinops sagax) and other pelagic fishes in the California Current Ecosystem during spring 2006, 2008, and 2010, estimated from acoustic-trawl surveys. Fish Bull 110:110-122

Submitted: August 16, 2016; Accepted: June 30, 2017

Proofs received from author(s): August 5, 2017 